\title{
Customized Service's Empirical Analysis And Exploration In LifeBased On Double O2O Mode-A Case Study Of 'Suning V Purchase'
}

\author{
Yi-peng LI and Di WANG* \\ School of Information and Safety Engineering, Zhong nan University of Economics \\ and Law, Wu Han 430073, China
}

Keywords: Customized Service, Double O2O Mode, Suning Commerce Group.

\begin{abstract}
With the rapid development of the Internet economy, people's consumption level is getting higher and higher, the demand for customized services is becoming increasingly apparent. At the same time double $\mathrm{O} 2 \mathrm{O}$ mode shine in the Internet Age. Based on the field investigation in Wuhan, this paper studies the practical application and development prospect of the customized service based on the double $\mathrm{O} 2 \mathrm{O}$ mode in our life, and deeply analyzes the market power and the future of this model. Organic integration of customized services and electronic consumption develops a new consumption space, and constantly leads the marketing mode to be innovative.
\end{abstract}

\section{Introduction}

With the development of the times, fierce competition brings more and more, better and better products to market. Consumers expect higher for the quality of products and services. The first, consumers' requirements for product type, size, design, color, variety, demand are getting diversification. Followed is that the product function, quality and reliability requirements are increasing day by day, and the requirements of this standard are based on different users' satisfaction. This situation leads to the uncertainty of the standard. The last one is to meet the demand of customization, while the price of products needs to be as low as mass production. Manufacturers will find that the best products are not designed for users, but they are designed with users. In this way, combined the double $\mathrm{O} 2 \mathrm{O}$ mode with the customized service, by using the advantages of double $\mathrm{O} 2 \mathrm{O}$ model and customized service, we can solve this problem perfectly.

\section{Double 020 mode shine in the Internet age.}

Double $\mathrm{O} 2 \mathrm{O}$ mode, that is a mode through opening up online and offline channels, based on the mobile Internet application technology, offline practical experience and the quantitative analysis of customer needs, with mutual evaluation and shared mechanism, accesses to the most authentic user data and realizes the classification of cloud computing. So that users can get perfect experiences.

\section{The need of customized service is growing day by day.}

With the rapid development of China economy, people's consumption levels are gradually developing towards the advanced stage, a very clear trend in market is that general consumption gradually turns to individual consumption. Consumers want to be able to enjoy their own personal services, and they will not enjoy this wonderful feeling alone, they will share with others. This reaches the positive effect of spread. And then the amplification effect comes into being, everyone wants to enjoy the "tailor-made" personalized service. 


\section{Customized service has broad prospects in double 020 Electronic Business field.}

Traditional $\mathrm{O} 2 \mathrm{O}$ e-commerce model(Online to Offline) is to guide consumers from online to offline, driving customer source only on the line, and there is no online and offline interactive mechanism. Consumer channels are single. The monotonous traditional $\mathrm{O} 2 \mathrm{O}$ mode already can't satisfy the needs of consumer market diversification. This is the beginning of the double $\mathrm{O} 2 \mathrm{O}$ mode. Double $\mathrm{O} 2 \mathrm{O}$ electronic business model achieves the interaction between online and offline. It lets the consumers have a clear understanding on each link.

When the customized service combines with double $\mathrm{O} 2 \mathrm{O}$ mode, we can realize reservation to complete the transaction on line and give consumers customized personality services. Fully meeting customer's needs makes them rely on double $\mathrm{O} 2 \mathrm{O}$ electronic consumption patterns. This will bring great convenience and wonderful life experience to consumers.

\section{Research content}

Through the field investigation and study of 'Suning V Purchase', we get the corresponding data informations. Combined with its development and market prospects, according to our own computer professional advantages and information management technology, we use SWTO method to analyze the data and get the advantages and disadvantages of customized service based on the double $\mathrm{O} 2 \mathrm{O}$ mode. To better determine the customized service in double $\mathrm{O} 2 \mathrm{O}$ mode development direction and the development of the structure. Explore the customized services best e-commerce mode in life. Strive to provide consumers with convenient, authentic, reliable and affordable services. Meet the personalized needs of the masses. Explore new business opportunities and market, conducting the e-commerce mode to a new height.

\section{Research purpose and meaning}

\section{The combination of double $\mathbf{O 2 O}$ mode and customized service forms a kind of new mode of electricity business.}

In the customization service system, consumer' needs and preferences are different. This requires a convenient communication between consumers and businesses. To meet the needs of customers' customized services and provide them with a safe and reliable trading environment, the best way is to fuse online and offline to trade, forming an integrated service. And the customized services that is based on double $\mathrm{O} 2 \mathrm{O}$ mode just fits to do this.

\section{Meet the customized service needs of consumers and achieve the diversification of the consumer market.}

Take a look at today's consumer market, most businesses can only provide the standardized service for the masses, they can't vary from person to person. Influenced by the international market, nearly two years, some of the domestic application of the customized services of small and medium enterprises gradually rise. For example, personalized wedding custom services, 'Internet+boosting household' customized service and so on. Such a personalized service can suit the actual situation of the consumers and satisfy reality and spiritual double needs. This personalized service can also bring new vitality and business opportunities to our market and promote the implementation of new marketing methods. 


\section{Explore the market potential vitality of customized service based on electronic business model}

Through this topic research, we have learnt consumers' response to this customized service based on double line $\mathrm{O} 2 \mathrm{O}$ model. Through in-depth investigation and analysis, we explore whether this kind of customized service based on the double line $\mathrm{O} 2 \mathrm{O}$ mode has the vitality of market, where is its development prospects, how to better achieve the promotion of customized services, etc...

\section{Research process and result analysis}

\section{Research process}

Market research and analysis flow chart

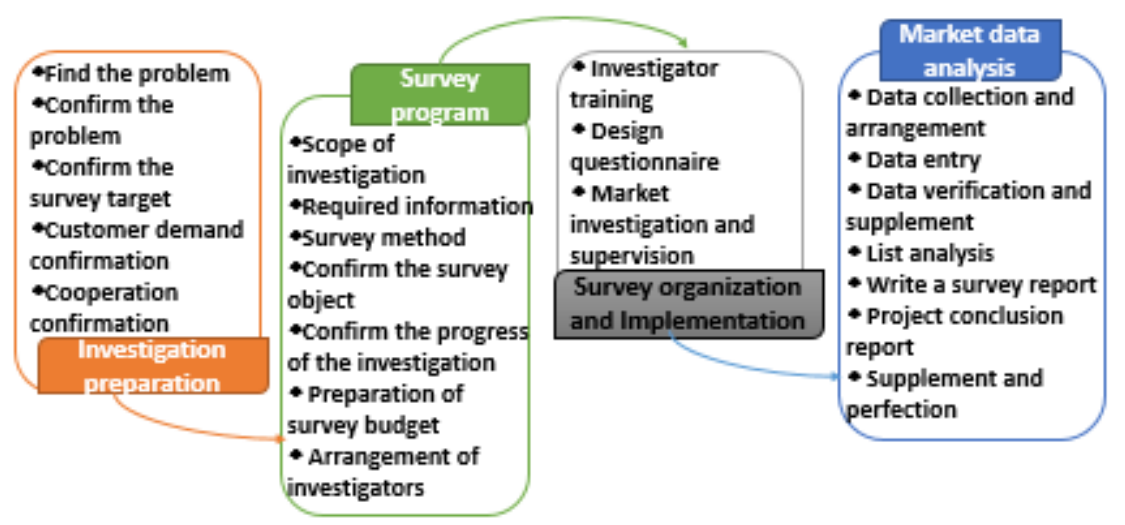

Figure1.Market research and analysis flow chart

For business investigation

Questionnaire survey of sex and age ratio
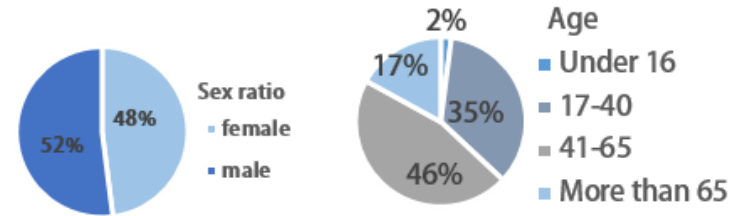

Figure2.Sex and age ratio

Respondents' understanding on double $\mathrm{O} 2 \mathrm{O}$ customized service

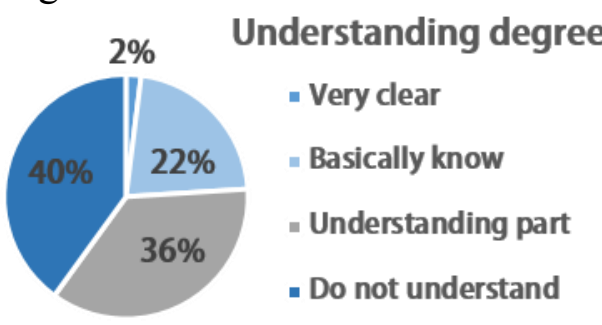

Figure 3.Understanding degree

Investigation object's main problems in the real business 


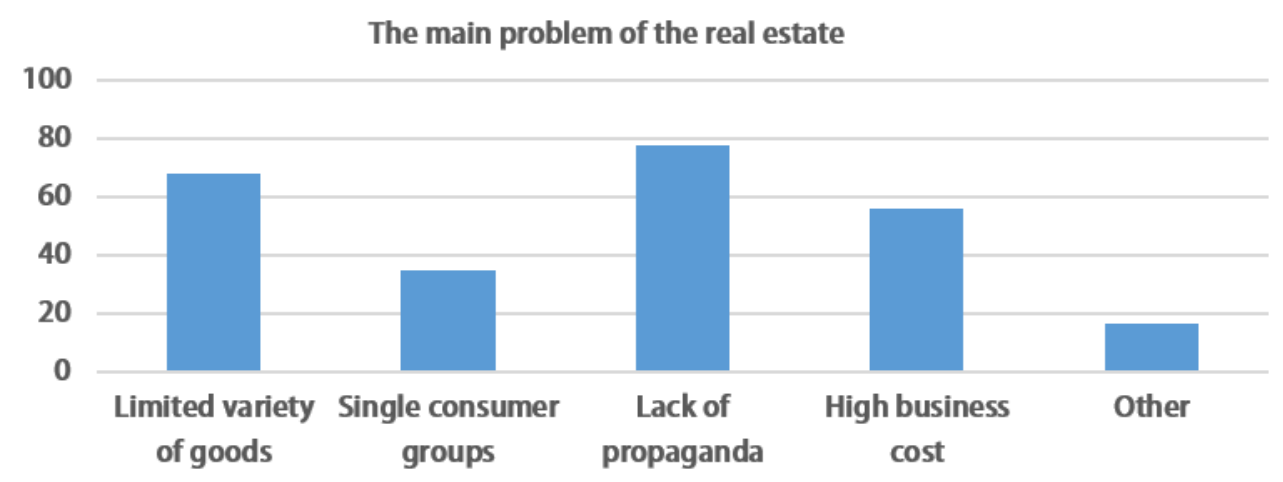

Figure4.The main problem of the real estate

Survey respondents think what can make improvements online

Online improvement

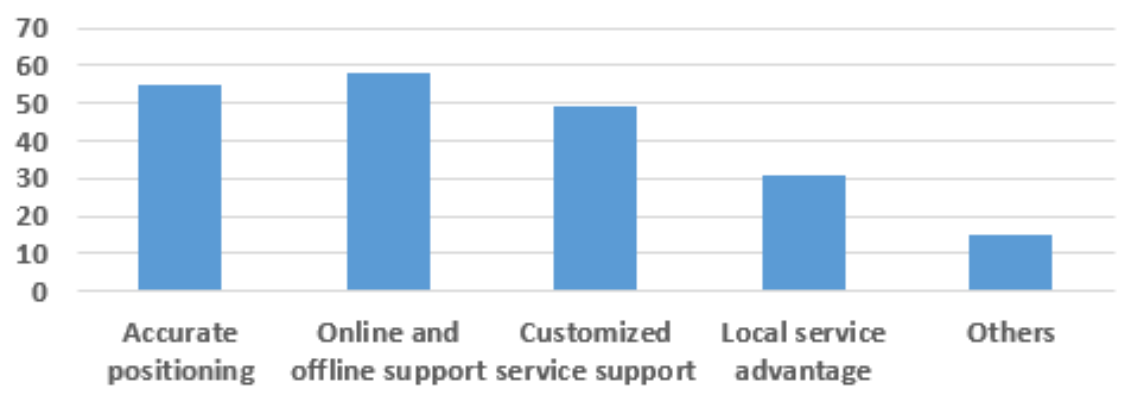

Figure 5.Online improvement

Survey respondents believe that what is the most important factor in the development of customized service model in two line $\mathrm{O} 2 \mathrm{O}$

The most important factor
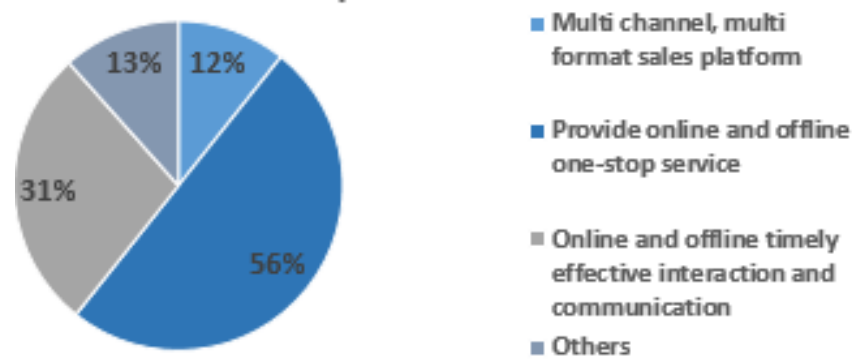

Figure 6.The most important factor

Whether double $\mathrm{O} 2 \mathrm{O}$ customized service mode promote the physical store and online store two-way change

\begin{tabular}{|l|r|r|r|r|}
\hline Business attitude & Yes & No & Will not change & it's hard to say \\
\hline The proportion & $73 \%$ & $6 \%$ & $8 \%$ & $13 \%$ \\
\hline
\end{tabular}

Figure 7

\section{Survey of consumers}

Questionnaire survey of sex and age ratio

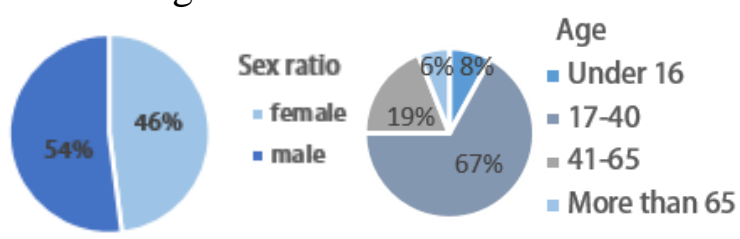

Figure 8.Sex and age ratio 
Respondents online spending

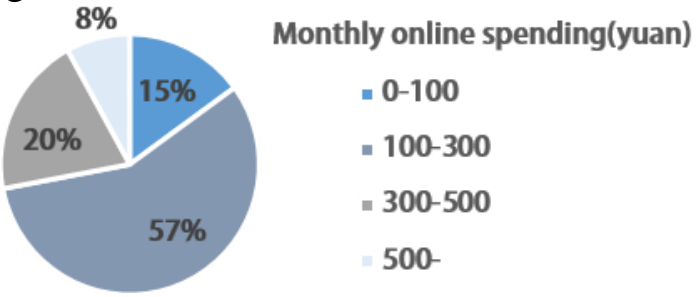

Figure 9.Monthly online spending

Consumers most concerned content

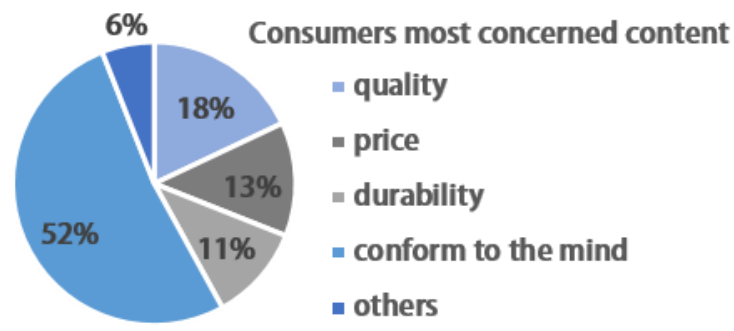

Figure 10.Consumers most concerned content

The advantages of double $\mathrm{O} 2 \mathrm{O}$ customized services compared to the commone online shopping

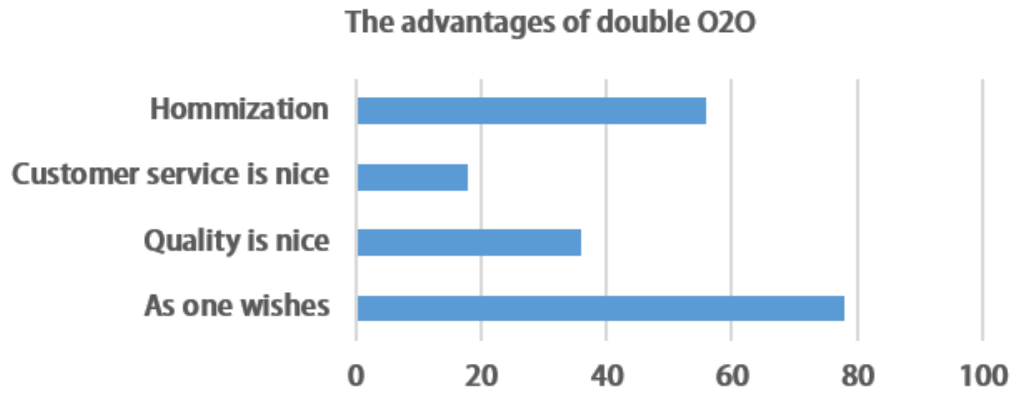

Figure 11.The advantages of double $\mathrm{O} 2 \mathrm{O}$ mode

The biggest drawbacks of double $\mathrm{O} 2 \mathrm{O}$ customized service The biggest drawbacks of double 020 customized service

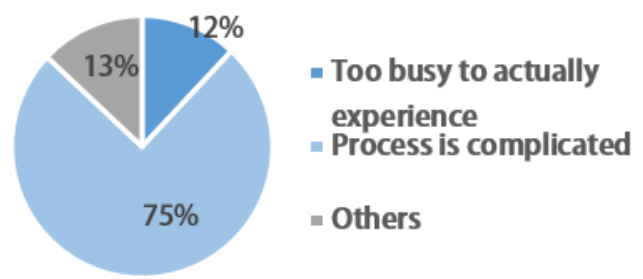

Figure 12.The biggest drawbacks of double $\mathrm{O} 2 \mathrm{O}$ mode cuntomized service

\section{Case analysis}

'Professional personages of home appliances' who engage in 'Suning V Purchase' have passed the certification of professional training or preparations for the job before mount guard. After booking on line, users will be able to enjoy their professional services in the store. For example, professional personages will provide consumers with a package of home appliance solutions according to the consumers' unit, budget, family members. This service is not limited to pre-sales consulting, it will be extended to distribution, 
installation, after-sales and all aspects of the problem solving and coordination at the same time.

The main advantages of 'Suning V Purchase' are as follows:

Increasinig the value of $\mathrm{V}$ purchase service itself allows customers to enjoy the exclusive shopping guide and get other levels of service. At the same time, it stimulates more users to take the initiative to choose $\mathrm{V}$ purchase services.

Appropriately increasing in some of user's personality and precision services will attract more users.

The main problems of 'Suning V Purchase' are as follows:

Although Suning goes very far in the road of two-line combination, but the implementation of the double O2O mode also makes Suning suffers pain. Due to the effect of investment on line is slow. Short-term profits are hitted. Suning cloud business achieves revenue 80.143 billion yuan in the first three quarters of this year, an increase of $10.65 \%$; net profit of 625 million yuan, down $73.41 \%$. Short-term competitive strategy will enable Suning to bear the weight of performance, but through the efforts to adjust the line under the store, the line of same price of online and offline and implementation of Third Party Open Platform Strategy in the future, maybe the company's online and offline market shares will be improved.

User targeting is not particularly obvious. 'Suning V Purchase' is to provide exclusive shopping guide service for VIP users, but these users are just a few. Suning entity stores have more ordinary users, they don't need VIP shopping guide service.

\section{Summary}

The advent of the mobile Internet era makes the fusion of online and offline be natural gradually. The time that single channel sings the one-man show has gone. On the road of transformation, some enterprises have made their own characteristics, achieving diversification of $\mathrm{O} 2 \mathrm{O}$, riching marketing patterns, and constantly leading the e-business model innovation. At the same time, with China's rapid economic development, consumer levels have risen, consumers want to be able to enjoy the personal service that meet the actual situation and the needs of reality and spirits.

According to the survey shows that based on double $\mathrm{O} 2 \mathrm{O}$ e-commerce model to achieve customized services is feasible. This consumption is more humanize. Product quality can be guaranteed. Consumers do not have to worry about after-sales service. But to implement this innovative sales model exactly, businesses have to pay the cost and bear the risk of considerable.

For example, the connection between information resources of online shop and physical store has increased cost; shopping links are so cumbersome that it leads to decline in sales; consumers' personal needs are difficult to fully meet and so on. Only the businesses have enough capital and lung power, identify the market positioning of customized services exactly and have great concentration to break through new markets, can a new world be opened.

Double $\mathrm{O} 2 \mathrm{O}$ mode and customization services will be the trend, but not for every industry. The transformation of entities to e-commerce usually does not really achieve synergy. Physical store have a large number of online stores and brand resources, in a new round of Ebb Tide, if businesses can find their own positioning and identify the customer source, grasp the market development direction and implement customized service effectively, they will be able to break through industry limitations and open up new markets. 


\section{Acknowledgement}

This research was financially supported by the National Natural Science Foundation of China [No.71401180].

\section{References}

[1]Suning "private custom" O2O model

[2] O2O dual line fusion: A new opportunity for transformation of the Internet industry prosperity

[3]Research on the standardization of service and customized service based on customer value 